\title{
Putative Receptors Underpinning L-Lactate Signalling in Locus Coeruleus
}

\author{
Valentina Mosienko ${ }^{1,2}{ }^{(1)}$, Seyed Rasooli-Nejad ${ }^{1,3}$, Kasumi Kishi ${ }^{1,4}$, Matt De Both ${ }^{5}$, \\ David Jane ${ }^{1}$, Matt J. Huentelman ${ }^{5}$, Sergey Kasparov ${ }^{1}$ and Anja G. Teschemacher ${ }^{1, *}$ \\ 1 Pharmacology and Neuroscience, School of Physiology, University of Bristol, Bristol BS8 1TD, UK; \\ v.mosienko@exeter.ac.uk (V.M.); seyed.rasooli-nejad@charite.de (S.R.-N.); kasumikishi@gmail.com (K.K.); \\ david.jane@bristol.ac.uk (D.J.); Sergey.Kasparov@bristol.ac.uk (S.K.) \\ 2 Institute of Biomedical and Clinical Sciences, University of Exeter Medical School, Exeter EX4 4PS, UK \\ 3 Neuroscience Research Centre, Medical University Berlin-Charité, D-10115 Berlin, Germany \\ 4 Institute of Science and Technology IST Austria, 3400 Klosterneuburg, Austria \\ 5 Center for Rare Childhood Disorders, Translational Genomics Research Institute, Phoenix, AZ 85004, USA; \\ mdeboth@tgen.org (M.D.B.); mhuentelman@tgen.org (M.J.H.) \\ * Correspondence: Anja.Teschemacher@bristol.ac.uk
}

Received: 14 October 2018; Accepted: 7 November 2018; Published: 16 November 2018

check for updates

\begin{abstract}
The importance of astrocytic L-lactate (LL) for normal functioning of neural circuits such as those regulating learning/memory, sleep/wake state, autonomic homeostasis, or emotional behaviour is being increasingly recognised. L-Lactate can act on neurones as a metabolic or redox substrate, but transmembrane receptor targets are also emerging. A comparative review of the hydroxy-carboxylic acid receptor (HCA1, formerly known as GPR81), Olfactory Receptor Family 51 Subfamily E Member 2 (OR51E2), and orphan receptor GPR4 highlights differences in their LL sensitivity, pharmacology, intracellular coupling, and localisation in the brain. In addition, a putative Gs-coupled receptor on noradrenergic neurones, LLRx, which we previously postulated, remains to be identified. Next-generation sequencing revealed several orphan receptors expressed in locus coeruleus neurones. Screening of a selection of these suggests additional LL-sensitive receptors: GPR180 which inhibits and GPR137 which activates intracellular cyclic AMP signalling in response to LL in a heterologous expression system. To further characterise binding of LL at LLRx, we carried out a structure-activity relationship study which demonstrates that carboxyl and 2-hydroxyl moieties of LL are essential for triggering D-lactate-sensitive noradrenaline release in locus coeruleus, and that the size of the LL binding pocket is limited towards the methyl group position. The evidence accumulating to date suggests that LL acts via multiple receptor targets to modulate distinct brain functions.
\end{abstract}

Keywords: L-lactate; hydroxy-carboxylic acid receptor; OR51E2; GPR4; GPR137; cAMP; locus coeruleus; noradrenaline; next generation sequencing; structure-activity relationship

\section{Introduction}

Astrocytes, the electrically nonexcitable "cousins" of neurones, are strategically placed at the interface between the periphery and neuronal networks of the central nervous system. Among other functions, they handle the import and distribution of glucose, the main energy substrate used by the brain, as well as its storage in the form of glycogen [1]. Glycolytic breakdown of glucose to pyruvate, and its subsequent conversion to L-lactate (LL), yields two units of ATP for intracellular energy transfer or, alternatively, for use as a transmitter. If glycolysis is followed by oxidative phosphorylation, nearly 20 times as much ATP can be produced. This, however, does not mean that almost all ATP in the 
cell is delivered by mitochondria. In fact, since glycolysis is very fast compared to the mitochondrial oxidation of pyruvate, the contribution of glycolysis to the pool of ATP may be comparable to that originating from oxidative phosphorylation [2], especially during peaks of high metabolic demand. In spite of the obvious discrepancy in energy efficiency, the brain produces large amounts of LL, much of which, surprisingly, is drained into the peripheral circulation [3]. The energetic or functional advantages of this metabolic imbalance are still controversial.

Average physiological extracellular levels of LL reported for the brain are in the sub- to low $\mathrm{mM}$ range, but they respond dynamically to plasma LL concentrations, central availability of oxygen, neuronal network activity, or metabolic triggers and can approach $\sim 10 \mathrm{mM}$ under extreme conditions such as seizure or hypoxia [4,5]. In principle, the ability to glycolytically process glucose to LL is shared by astrocytes and neurones, but astrocytes are held to be the main source of LL in the brain, at least under physiological resting conditions where there is a steeper intra-to-extracellular LL gradient in astrocytes as compared to neurones [6]. Astrocytes are known to tolerate hypoxic conditions better than neurones and may more easily upregulate glycolytic activity to bridge periods of oxygen demand exceeding supply [7]. Indeed, they have been shown to switch to aerobic glycolysis while sparing the limited oxygen for neuronal oxidative phosphorylation [8]. According to the astrocyte-to-neuron-lactate-shuttle (ANLS) hypothesis, the astrocyte-derived LL may benefit neurones as an additional energy substrate to sustain periods of elevated activity $[6,9,10]$.

Whether as a valuable energy substrate or a glycolytic waste product, LL has been reported to modulate brain activity and behaviour in various functional contexts [5]. LL was shown to be essential in certain learning and memory paradigms ([11,12]; reviewed in [13]). It is also important for regulating sleep/wake states at the level of the lateral hypothalamic area, as well as negatively correlating with sleep-associated slow wave activity in the cortex [14-16]. Moreover, recent evidence suggests that it acts as an antidepressant in an animal model of depression [17]. Since central cyclic AMP (cAMP) signalling was found to be reduced in depressed patients, this could potentially be explained by the ability of LL to increase cAMP responses in astrocytes and some neuronal phenotypes [18-20].

We have previously reported a mechanism that is consistent with, and may contribute to, LL's overall role as a central activator and regulator of brain state. We found that optogenetically induced release of LL from astrocytes into the extracellular space triggers noradrenaline (NA) release from adjacent noradrenergic neurones [20]. When microinjected into the locus coeruleus (LC) area, LL desynchronised the electroencephalogram activity in the cerebral cortex, indicating that the noradrenergic network was excited [20].

It is becoming increasingly clear that LL utilises a wide variety of signaling mechanisms to influence physiological outputs. These include not only multiple intracellular targets but also effects on putative receptors located on the plasma membrane of the cells.

\subsection{Targets and Mechanisms of L-Lactate Signalling in the Brain}

Upon import into neurones, LL can be reduced to pyruvate, raising the NADH/NAD+ ratio and switching on NMDA receptor-dependent immediate early gene expression ([21]; Figure 1). This pathway has been suggested to underlie some of the effects of ANLS, for example, memory formation [13]. A distinct pathway that may allow LL to exert long-term effects is via binding to and stabilizing the protein NDRG3 which, in turn, activates kinase activity in favour of Raf-Extracellular signal-regulated kinase signalling to support the tissue response to prolonged hypoxia [22].

In terms of reversible short-term metabolic signalling by LL, ATP-sensitive potassium channels have been suggested as an intracellular target. Analogous to the scenario in pancreatic beta cells, inhibition of these channels by LL-derived ATP increased excitation of orexin neurones in the hypothalamus during arousal [14,23].

In some instances, however, the effects of LL are not consistent with an intracellular action but can only be explained by activation of membrane-associated receptors from the extracellular side. The first specific LL receptor to be characterised was the G-protein coupled receptor (GPR) GPR81, currently 
known as hydroxy-carboxylic acid receptor 1 (HCA1). Over recent years, further LL membrane receptor candidates have been identified, and the list is likely to lengthen (Figure 1).

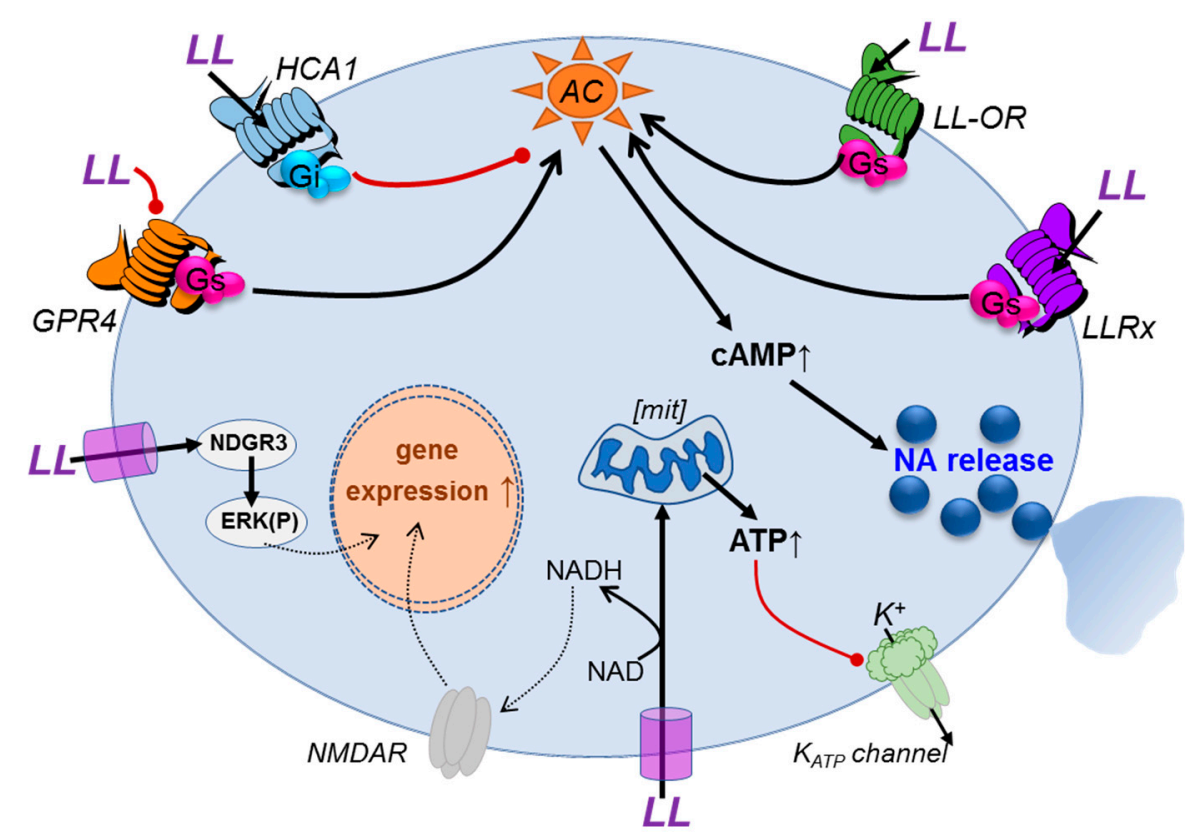

Figure 1. Summary of potential L-lactate (LL)-mediated signalling actions in neurones. L-lactate which is transported into the cell can be metabolised and/or influence gene expression, e.g., via NMDA receptor modulation or ERK pathway activation. Increased ATP production can inhibit $\mathrm{K}_{\mathrm{ATP}}$ channel activity and increase cell excitability. LL may also act via a range of surface G-protein coupled receptors to stimulate or inhibit cAMP-dependent signalling, such as NA release in noradrenergic neurones. Black arrows indicate stimulatory action, red lines illustrate inhibitory effect. AC-adenylate cyclase; ERK(P)—phosphorylation of extracellular signal-regulated kinases; GPR4—orphan G-protein-coupled receptor 4; HCA1—hydroxy-carboxylic acid receptor; LL-OR_LL-activated olfactory receptor; LLRx — LL receptor on noradrenergic neurones; [mit]—mitochondria; NA—noradrenaline; NMDAR—NMDA receptor.

\subsection{Hydroxy-carboxylic acid receptor (HCA1)}

HCA1 was the first G-protein-coupled receptor (GPCR) to be described that is activated selectively by LL and a few related monocarboxylates (Table 1). In adipocytes where HCA1 was discovered, this leads to inhibition of lipolysis under conditions of glucose abundance in the fed state $[24,25]$. It has been reported that HCA1 is also expressed at low levels in the brain, predominantly in neurones, in cerebellum, hippocampus, and neocortex [26]. We carried out RNA sequencing on samples of neurones dissociated from the LC of rats and were unable to confirm its expression in these cells (Table 2). HCA1 is a $\mathrm{G}_{\mathrm{i}}$-protein-coupled receptor and its activation inhibits cAMP production $\left(\mathrm{IC}_{50}\right.$ in vitro according to various sources is between $5-30 \mathrm{mM}$; [25-27]. The stereoisomer of LL, D-lactate (DL), also a weak agonist at HCA1 (Table 1; [25]).

In spite of its low potency, site-directed mutagenesis and molecular modelling predicts that LL binds specifically as a typical GPCR ligand rather than an allosteric modulator [25]. Being a $\mathrm{G}_{\mathrm{i}}$-coupled receptor, HCA1 should evoke inhibitory effects (hyperpolarisation of the membrane and inhibition of transmitter release), which is opposite to what we found in noradrenergic neurones ([20]; Figure 1). In cultured embryonic cortical neurones, LL inhibited $\mathrm{Ca}^{2+}$ signalling in a pertussin toxin-sensitive manner with a half-maximal inhibitory concentration $\left(\mathrm{IC}_{50}\right)$ of $\sim 5 \mathrm{mM}$ [28]. Since this effect was mimicked by the HCA1 agonist 3,5-dihydroxybenzoic acid (3,5-DHBA), it was indeed consistent with signalling via HCA1. 
Table 1. Characteristics of the known L-lactate receptors.

\begin{tabular}{|c|c|c|c|c|c|}
\hline Receptor & $\begin{array}{l}\text { LL Potency } \\
\text { (Range) }\end{array}$ & $\begin{array}{l}\text { Intracellular } \\
\text { Signalling }\end{array}$ & Other Agonists & Antagonists & References \\
\hline HCA1 & 5-30 mM & $\mathrm{Gi}, \mathrm{cAMP} \downarrow$ & $\begin{array}{l}\text { 3,5-DHBA; } \alpha \text {-HBA; } \\
\text { glycolate; } \gamma \text {-HBA }\end{array}$ & nd & {$[25,26]$} \\
\hline OR51E2 & $\sim 4 \mathrm{mM}$ & Gs, cAMP $\uparrow$ & $\begin{array}{c}\text { Acetate; } \\
\text { propionate }\end{array}$ & nd & [29] \\
\hline GPR4 & $1-10 \mathrm{mM}$ & $\begin{array}{c}\text { allosteric } \\
\text { modulation? }\end{array}$ & $\mathrm{H}^{+}$ & NE 52-QQ57 & [30] \\
\hline LLRx & $0.5 \mathrm{mM}$ & Gs, cAMP $\uparrow$ & $\begin{array}{c}\text { MPA; aHIBA; } \\
\text { HMBA; 2HPA; KA } \\
\text { (see Figure 2) }\end{array}$ & D-lactate & [20] \\
\hline \multicolumn{6}{|c|}{$\begin{array}{l}\text { 3,5-DHBA (3,5-dihydroxybenzoic acid), } \alpha \text {-HBA ( } \alpha \text {-hydroxybutyrate), } \gamma \text {-HBA }(\gamma \text {-hydroxybutyrate); aHIBA } \\
\text { ( } \alpha \text {-hydroxyisobutyric acid), HMBA (2-hydroxy-3-methyl-butyric acid), 2HPA }((S) \text {-2-hydroxypentanoic acid, } \\
\text { MPA ((S)-(-)-2-methoxy-propionic acid), nd-not determined, LL-L-lactate. LLRx-putative LL receptor } \\
\text { on noradrenergic neurones, GPR4—orphan G-protein-coupled receptor 4; OR51E2-LL-sensitive olfactory } \\
\text { receptor; HCA1-Hydroxy-carboxylic acid receptor; Gi-G } \mathrm{G}_{\mathrm{i}} \text {-protein activation; Gs-G } \mathrm{G}_{\mathrm{s}} \text {-protein activation; } \\
\text { KA-kynurenic acid. }\end{array}$} \\
\hline
\end{tabular}

Table 2. Expression of known L-lactate receptors in locus coeruleus neurones and astrocytes as determined by RNA sequencing.

\begin{tabular}{ccccc}
\hline Gene Product of Interest & LC (p29) & LC $(\mathrm{p} 7)$ & LC Neurones & Astrocytes \\
\hline DbH & 43.3 & 527.7 & 3556.2 & 2.5 \\
$\boldsymbol{\alpha}_{\mathbf{2}} \mathrm{A}-\mathrm{AR}$ & 116.8 & 307.0 & 268.4 & 115.9 \\
HCA1 & 0.0 & 0.0 & 0.0 & 0.0 \\
OR51E2 & 7.6 & 21.3 & 0.0 & 0.0 \\
GPR4 & 70.5 & 26.0 & 34.6 & 24.5 \\
\hline
\end{tabular}

Dopamine- $\beta$-hydroxylase ( $\mathrm{DbH})$, shown for reference as a marker of noradrenergic neurones, is highly expressed in locus coeruleus (LC) tissue from 29- and 7-day-old rats, and in dissociated noradrenergic neurones (area A6) from organotypic brain cultures. Values for a canonical GPCR, $\alpha 2 \mathrm{~A}$-adrenoceptor $(\alpha 2 \mathrm{~A}-\mathrm{AR})$, provide a reference for the expression levels of this class of proteins. In comparison, known L-lactate receptors are found at low to negligible levels and not specifically on LC neurones. Numbers represent average FKPM (fragments per kilobase of exon per million fragments mapped) from duplicates. GPR4-orphan G-protein-coupled receptor 4; OR51E2-LL-sensitive olfactory receptor; HCA1-Hydroxy-carboxylic acid receptor.

\subsection{Olfactory L-Lactate Receptors}

More recently, OR51E2, a further LL-activated GPCR, has been reported in the mouse. OR51E2 belongs to the family of olfactory receptors which invariably couple to a specific subset of $\mathrm{G}_{\mathrm{s}}$-proteins, thereby increasing cAMP levels (Figure 1). The $\mathrm{EC}_{50}$ for cAMP elevation in vitro by LL was determined as $4 \mathrm{mM}$ (Table 1; [29]). As expected, the OR51E2 receptor is found in the rodent olfactory bulb but it is also ectopically expressed in brain and periphery, for example, in glomus cells in the carotid body where its role in activation of carotid sinus nerve activity by LL is currently debated [29,31,32]. Olfactory receptors that are LL-sensitive may be involved in the maladaptive increase in sympathetic drive associated with the progression of chronic heart failure, in a vicious circle that leads to further deterioration of ischemic conditions and lactate acidosis [33,34].

Ectopic localisation of this olfactory receptor also extends to autonomic ganglia and to the brain, predominantly brainstem areas $[35,36]$. Since we previously showed that $\mathrm{G}_{\mathrm{s}}$-coupling was involved in LL-mediated stimulation of noradrenergic transmission [20], we checked our transcriptomic data and found OR51E2 expression in LC tissue, but were unable to confirm its expression in isolated LC neurones (Table 2). We suggest that, since expression levels are low and the receptor appears to be not specifically localised to noradrenergic neurones, it is unlikely to account for the central effects of LL we had described earlier. 
Nevertheless, in a study to follow up olfactory perception of LL, we discovered that not only mice but also humans can detect the odour of LL. However, OR51E2 knockout mice were still able to smell it [37]. This points to the existence of one or more additional LL-sensitive olfactory receptors which, if also expressed in the brain, would be expected to contribute to cAMP-mediated LL signalling. At the same time, olfactory receptors are notorious for their broad spectrum of activating ligands and are expected to act cooperatively to identify specific odorants.

\subsection{Orphan G-protein-coupled receptor 4 (GPR4)}

Since LL is one of the main extracellular organic acids, we investigated whether a proton-sensitive $\mathrm{G}_{\mathrm{s}}$-protein-coupled receptor, GPR4, may mediate or be modulated by LL ([38]; Figure 1, Table 1). Our evidence suggested that GPR4 contributes to the compensatory ventilatory response to increased $\mathrm{CO}_{2}$ levels in hypercapnic conditions. However, we found that, under physiological blood and brain LL concentrations, GPR4 is partially inhibited by LL and its sensitivity to protons is reduced [30].

GPR4 is prominently expressed in the endothelium of blood vessels, in periphery as well as brain [30]. Localisation in certain neuronal phenotypes such as in retrotrapezoid and raphe nuclei, rostral ventrolateral medulla, septum, and LC in the mature rodent brain has also been demonstrated [30,39]. We detected a low level of expression in the LC (Table 2). However, since LL appears as a negative, presumably allosteric, modulator of GPR4-mediated cAMP production, it cannot be responsible for the effects of LL we observed on noradrenergic neurones [20]. Considering the comparatively minor impact of GPR4 on cardiorespiratory regulation and its wide distribution in the brain, including the raphe nuclei and related areas, it may be modulating processes mediated by these areas, an issue which remains to be investigated [30]. In setting the cAMP tone and levels of neuronal excitability it might, for instance, be involved in regulation of anxiety and depression.

\subsection{The L-Lactate Receptor Responsible for Central noradrenaline Release}

The receptor that mediates the effect of LL-induced NA release (LLRx) in the brain has not been identified to date. Our previous findings defined several properties for LLRx-mediated NA release ([20]; Figure 1): LL activates LLRx from the extracellular side and does not require entry into the cell. LL has a higher potency, by $\sim 10$-fold or more, at LLRx as compared to other so far identified LL receptors and is activated around the physiologically relevant LL concentrations in the healthy brain $(0.2-0.5 \mathrm{mM})$. This makes it suitable for picking up physiologically relevant dynamic changes. The activation of LLRx by LL is inhibited in the extracellular presence of its stereoisomer DL. LLRx is most likely a $\mathrm{G}_{\mathrm{s}}$-coupled receptor as the effect of its activation depended on adenylate cyclase [20].

Since none of the receptors discussed above fits these requirements, our hypothesis is that LL activates one of the orphan G-protein-coupled receptors present in the brain and expressed by noradrenergic neurones. In the current study, we tested an array of LL derivatives for their ability to mimic the LL effect on NA release in order to further characterise the structural requirements for agonists of LLRx. In addition to the primary aim of these experiments, i.e., to establish a structure-activity relationship (SAR) between the LL molecule and LLRx to aid molecular modelling, a second objective was to lay the basis for antagonist and superagonist development. In addition, we carried out next-generation sequencing of neurones in the LC and identified orphan GPCRs which are expressed. We tested a selection of these in heterologous expression systems for their ability to activate $\mathrm{G}_{\mathrm{s}}$-proteins in response to LL stimulation.

\section{Materials and Methods}

\subsection{Chemicals}

Analogues of LL in which carboxyl-, hydroxyl-, or methyl groups were modified were obtained from commercial sources: 2-hydroxy-2-propan-sulfonic acid from Alfa Aesar (Heysham, UK); ( \pm )-3-hydroxy-2-methylbutyric acid, 1-hydroxycyclo-propane-carboxylic acid, 
and (S)-tetrahydro-furoic acid from Acros Organics (Thermo Fisher Scientific, Waltham, MA, USA); and kynurenic acid from Abcam (Cambridge, UK). All other analogues and reagents were obtained from Sigma-Aldrich (Merck, Darmstadt, Germany), unless stated otherwise. L-Lactate and analogues, acetate, and pyruvate were diluted in $\mathrm{ddH}_{2} \mathrm{O}$, adjusted to $\mathrm{pH}$ 7.4, and used at a final concentration of $2 \mathrm{mM}$ unless otherwise specified. To evaluate blocking by DL, DL was co-applied with LL or LL analogues at a final concentration of $200 \mu \mathrm{M}$.

\subsection{Organotypic Brain Slice Preparation}

All animal procedures were performed in accordance with the UK Animals (Scientific Procedures) Act, 1986, and covered by, PPL 30/3121.

Brainstem slice cultures were prepared as described previously [20]. In brief, 6-7-day-old Wistar rat pups were terminally anaesthetised and decapitated, and the brainstem was immediately removed. Slices of $200 \mu \mathrm{m}$ thickness were cut at the level of the LC in ice-cold sterile dissection medium (in mM: kynurenic acid 1; Hepes 1; glucose 20; $\mathrm{MgCl}_{2} 10$ ) using a vibrating microtome (7000 smz, Campden Instruments, Loughborough, UK). Slices were plated onto cell culture inserts (Millicell PICMORG50, Millipore, Watford, UK) and supplied with $1 \mathrm{~mL}$ per well feeding medium (Opti-MEM; 51985-026, Thermo Fisher Scientific, Loughborough, UK) supplemented with $25 \%$ fetal bovine serum, $25 \mathrm{mM}$ glucose, and $1 \%$ penicillin $(10,000$ units)/streptavidin $(10 \mathrm{~mL} / \mathrm{L}))$. To visualise noradrenergic neurones in the LC, we added $\sim 10^{9} \mathrm{TU} / \mathrm{mL}$ of the adenoviral vector (AVV) AVV-PRSx8-EGFP, which results in green fluorescent protein (EGFP) expression under PRSx8 promoter control [40]. To enable visualisation of astrocytes, an AVV with transcriptionally enhanced glial fibrillary acidic protein (GFAP) promoter was used to express EGFP (AVV-sGFAP-EGFP; [41]). Slices were kept at $37{ }^{\circ} \mathrm{C}$ and in $5 \% \mathrm{CO}_{2}$ for 7-12 days prior to experiments to allow for AVV-mediated protein expression.

\subsection{Fluorescence-Activated Cell Sorting and RNA Sequencing of Locus Coeruleus Neurones and Astrocytes}

Organotypic brain slices including LC were transduced with AVV-PRSx8-EGFP or AVV-sGFAP-EGFP. The LC area was dissected, and cells were dissociated as described previously [42], with modifications. The tissue was first digested at $37^{\circ} \mathrm{C}$ for $10 \mathrm{~min}$ in $5 \mathrm{ml}$ of Hank's Balanced Salt solution (HBS) in mM: $136 \mathrm{NaCl}, 5.3 \mathrm{KCl}, 4.1 \mathrm{NaHCO}_{3}, 1.6 \mathrm{CaCl}_{2}, 0.8 \mathrm{MgSO}_{4}, 0.44 \mathrm{KH}_{2} \mathrm{PO}_{4}$, $0.13 \mathrm{Na}_{2} \mathrm{HPO}_{4}, 10 \mathrm{HEPES}, 5.5 \mathrm{D}$-glucose) containing $30 \mathrm{U}$ of papain (Sigma-Aldrich / Merck, Darmstadt, Germany) under orbital shaking, before washing off the papain and triturating with a fire-polished Pasteur pipette. Cells were gently pelleted ( $3 \mathrm{~min}, 900 \mathrm{rpm}$ ), resuspended in HBS, and filtered through a $50 \mu \mathrm{m}$ mesh. EGFP-positive cells were sorted using $488 \mathrm{~nm}$ laser excitation and 510-550 nm emission in a Becton Dickinson InFlux cell sorter (BD Biosciences, Franklin Lakes, NJ, USA) running BD Software version 1.2. Viable cells were identified based on light scatter and the exclusion of propidium iodide. In addition, single-cell gating was used to exclude doublets and aggregated cells. Following fluorescence-activated cell sorting (FACS), more than 100 cells were collected into $100 \mu \mathrm{L}$ of $2 \%$ Triton in phosphate-buffered saline containing $1 \mu \mathrm{L}$ RNAseOUT (Invitrogen, Thermo Fisher Scientific, Loughborough, UK), and stored at $-80{ }^{\circ} \mathrm{C}$ until processed further.

Sequencing libraries for next-generation sequencing (NGS) were prepared with $250 \mathrm{ng}$ of total RNA using Illumina's Truseq RNA Sample Preparation Kit v2 (Illumina, Inc., San Diego, CA, USA) following the manufacturer's protocol. Final PCR-enriched fragments were validated on a 2200 TapeStation (Agilent Technologies, Santa Clara, CA, USA) and quantitated via qPCR using Kapa's Library Quantification Kit (Kapa Biosystems, Wilmington, MA, USA) on the QuantStudio 6 Flex Instrument (Thermo Fisher, Waltham, MA, USA). The final library was sequenced by 50 bp paired-end sequencing on a HiSeq 2500 (Illumina). Illumina BCL files were converted and demultiplexed (bcl2fastq 2.17). FASTQ files were trimmed of adapter sequences (CutAdapt 1.8.3) and aligned to rn5 (STAR 2.5). Aligned reads were summarised as gene-level counts (featureCounts 1.4.4) and as transcripts per million (Kallisto 0.43.0). Sequencing and quality control reports were generated (FastQC 0.11.4 and 
Qualimap 2.1.3). Pairwise differential expression analysis was conducted with the R package DESeq2 $(1.10 .1)$

\subsection{Measurement of Noradrenaline Release}

In our earlier study, we used fast scan cyclic voltammetry to detect NA release in organotypic slices of the LC in response to LL stimulation. Here, in order to expand selection of LL analogues tested and to increase throughput, we implemented an approach based on cell-based neurotransmitter fluorescent engineered reporter cells (CNiFERs; Supplementary Materials Figure S1) [43]. CNiFERs are derived from a HEK293 cell line that stably expresses the $\mathrm{Ca}^{2+}$ indicator TN-XXL and a human $\alpha 1$ adrenoreceptor. Binding of NA to the adrenoceptor activates $G_{q}$-protein signalling, leading to an increase in cytosolic $\mathrm{Ca}^{2+}$ through the phospholipase $\mathrm{C}$-inositol triphosphate pathway which is imaged through the FRET ratio of TN-XXL (Supplementary Materials Figure S1A,B). CNiFERs showed nanomolar sensitivity to NA $\left(\mathrm{EC}_{50}=31 \pm 1.75 \mathrm{nM}\right)$.

To monitor NA release from organotypic brain slices, $4 \times 10^{5} \mathrm{CNiFERs}$ were plated $24 \mathrm{~h}$ prior to experiments on a cell culture insert (Supplementary Materials Figure S1C). Imaging experiments were performed at $34{ }^{\circ} \mathrm{C}$ under continuous perfusion $(150 \mathrm{~mL} / \mathrm{h}$ ) with HEPES-buffered solution (HBS, pH 7.4; in mM: $\mathrm{NaCl} 138 ; \mathrm{KCl} 5.5 ; \mathrm{Na}_{2} \mathrm{HPO}_{4}$ 0.25; $\mathrm{KH}_{2} \mathrm{PO}_{4}$ 0.5; $\mathrm{CaCl}_{2}$ 1.67; $\mathrm{MgSO}_{4} 0.8 ; \mathrm{NaHCO}_{3}$ 4.25; HEPES 10; Glucose 5.5) in a tissue chamber mounted on a Leica SP5 confocal microscope. Images were collected in a time-lapse mode $(0.25 \mathrm{~Hz})$ with excitation at $458 \mathrm{~nm}$ and dual emission set to 462-501 nm (Citrine) and 519-595 nm (ECFP). Fluorescence intensities of Citrine and ECFP channels were exported and analysed offline in Excel (Microsoft, Redmond, WA, USA). The FRET ratio (ECFP/Citrine) was calculated, plotted against time, and the area under the curve (AUC) following LL/analogue stimulation was determined as FRET ratio $x \mathrm{~s}$. CNiFER responses were calibrated against $100 \mathrm{nM}$ NA to allow evaluation of total NA release in $\mathrm{nM} x \mathrm{~s}$.

\subsection{Patch Clamp of Noradrenergic Neurones}

Cultured slices containing the LC and transduced with an AVV-PRSx8-eGFP were transferred to a recording chamber mounted on an upright SP-2 confocal microscope (Leica, Wetzlar, Germany) and continuously superfused with HEPES-buffered solution (in $\mathrm{mM}: \mathrm{NaCl} 137, \mathrm{KCl}$ 5.4, $\mathrm{Na}_{2} \mathrm{HPO}_{4}$ $0.25, \mathrm{KH}_{2} \mathrm{PO}_{4}$ 0.44, $\mathrm{CaCl}_{2} 1.3, \mathrm{MgSO}_{4}$ 1.0, $\mathrm{NaHCO}_{3}$ 4.2, HEPES 10, Glucose 5.5; $\left.\mathrm{pH} 7.4\right)$ at $34 \pm 1{ }^{\circ} \mathrm{C}$. Current-clamp whole-cell recordings were sampled at $10 \mathrm{kHz}$ using an AxoClamp 2B amplifier (Molecular Devices, San Jose, CA, USA) and a 1401 interface with Spike 2 software (CED, Cambridge, UK). Recording pipettes were pulled with a vertical puller (Narishige PC-10) to 3-5 M 2 resistance and filled with pipette solution (in mM: potassium gluconate 130, HEPES 10, EGTA 5.5, $\mathrm{NaCl} 4, \mathrm{MgCl}_{2} 2$, $\mathrm{CaCl}_{2}$ 1, ATP 2, GTP 1, and glucose 5). After recording 5-10 min of stable baseline in current clamp, LL or its analogues were superfused with the chamber solution for 5-10 min.

\subsection{GloSensor Assay of Intracellular cAMP Accumulation}

Clones of a selection of human orphan GPCR open reading frames were commercially obtained: GPR61 and GPR176 from cDNA Resource Center (www.cdna.org); GPR81, GPR137, GPR137B, GPR158, GPR180 from SourceBioScience (www.sourcebioscience.com); GPR155 from Origene (www.origene. com); rodent GPR162 was synthetised by Eurofins Scientific (www.eurofins.co.uk). The open reading frames of the receptors were cloned into the expression plasmid pEGFP-N1 under control of the human cytomegalovirus promoter, upstream of a human internal ribosomal entry site, followed by the enhanced green fluorescent protein sequence.

The GloSensor assay was used for cAMP measurements as previously described, with modifications [42]. HEK293 cells were plated in 96-well white polystyrene plates (Greiner Bio-One, Kremsmünster, Austria) in DMEM media (Gibco, Thermo Fisher Scientific, Loughborough, UK) supplemented with $10 \%$ fetal bovine serum and $1 \%$ penicillin $(10,000$ units $) /$ streptavidin $(10 \mathrm{~mL} / \mathrm{L}))$, at a density of $4 \times 10^{5}$ cells $/ \mathrm{mL}$ to achieve $\sim 70 \%$ confluence for transfection. After $20 \mathrm{~h}$, cells were 
transiently co-transfected with the GloSensor cAMP plasmid GLO22F and a plasmid encoding the GPCR of interest using Trans-IT 293 (Mirus) according to the manufacturer's protocol. Transfection efficiency was confirmed by fluorescent visualisation of EGFP. Twenty-six hours after the transfection, cells were incubated with $850 \mu \mathrm{M}$ beetle luciferin potassium salt (Promega, Southampton, UK) at $\mathrm{pH}$ 7.4 for $2 \mathrm{~h}$ in the dark. Prior to adding drugs, media was changed to HBS (Gibco) buffered with $20 \mathrm{mM}$ HEPES and titrated to the desired $\mathrm{pH}$. Cells were incubated with LL for $20 \mathrm{~min}$ in a final well volume of $100 \mu \mathrm{L}$. Luminescence measurements of cAMP accumulation were obtained using an Infinite M200 PRO microplate reader (Tecan, Männedorf, Switzerland).

\subsection{Statistical Analysis}

Data are expressed as mean \pm standard error of the mean (SEM). Groups were compared using Student's $t$-test or one-way ANOVA as indicated. GraphPad Prism (version 7; La Jolla, CA, USA) was used for data processing and to calculate $\mathrm{EC}_{50}$.

\section{Results}

\subsection{L-Lactate Releases Noradrenaline from Locus Coeruleus Neurones}

To detect LL-induced release of NA we used a cell-based reporter system developed in D. Kleinfeld's laboratory [43]. These " $\alpha 1$ CNiFER" cells respond with a robust $\mathrm{Ca}^{2+}$ increase to NA which is registered through a ratiometric $\mathrm{Ca}^{2+}$ indicator which they express. Consistent with our previous observations using fast-scan cyclic voltammetry, a transient change in $\alpha 1$ CNiFER cell signals confirmed that LL ( $2 \mathrm{mM}$ ) evokes NA release from LC neurones in organotypic slices. As we previously reported, this effect was blocked by DL $(200 \mu \mathrm{M})$ and was independent of the caloric value of LL since neither pyruvate nor acetate (2 mM) triggered NA release [20] (Supplementary Materials Figure S1D).

\subsection{Structural Requirements for the Agonistic Action of L-Lactate on Noradrenaline Release}

In order to characterise the structural features required for LL binding to LLRx, we chose commercially available LL analogues in which the carboxyl, hydroxyl, or methyl groups were modified (Figure 2A-D). In addition, the effect of chain extension by increasing the distance between the $\mathrm{OH}$ and the carboxylate group of LL (e.g., 4, Figure 2C) or replacing the methyl group of LL with longer alkyl $(\mathbf{9}, \mathbf{1 0})$ or aralkyl chains (13-15, Figure 2D) was studied. Conformational restriction by carbocyclic (5) or heterocyclic ring $(\mathbf{7}, \mathbf{1 1})$ formation was also investigated (Figure 2C,D). Each analogue was tested at $2 \mathrm{mM}$ for its ability to evoke NA release, and the response was normalised to the effect of equimolar LL tested in the same slice (Figure 2E).

L-lactate analogues with modified carboxyl (1), hydroxyl (3), and methyl groups (8-10 and 15) and the heterocyclic analogues ( 7 and 11) stimulated NA release; however, none of these were significantly more efficacious than LL (Figure 2E). All other test compounds (2, 4-6, 12-14) evoked significantly smaller responses, leading to less than $50 \%$ of the NA release triggered by LL application (Figure 2E). We then further focused on the 8 active LL analogues to test for antagonistic properties of DL, and found that analogues (S)-(-)-2-methoxypropionic acid (3, MPA; Figure 2C), $\alpha$-hydroxyisobutyric acid (8, aHIBA; Figure 2D), 2-hydroxy-3-methylbutyric acid (9, HMBA; Figure 2D), (S)-2-hydroxyl-pentanoic acid (10, 2HPA; Figure 2D), and kynurenic acid (11, KA; Figure 2D) fulfilled the criteria for mimicking the effect of LL on NA release (Figure 2F; [20]).

We have previously shown that the effect of LL on NA release was paralleled by depolarisation of noradrenergic neurones, increasing their excitability [20]. In the current set of experiments, we extended this dataset and compared resting membrane depolarisation caused by LL with the effect of LL analogues (Table 3; Supplementary Materials Figure S2). L-lactate, aHIBA (8, Figure 2D), and HMBA (9, Figure 2D) caused depolarisation in a significant proportion of neurones. However, MPA (3, Figure 2C), 2HPA (10, Figure 2C), and KA (11, Figure 2C), also powerful NA-releasing LL mimetics, 
evoked no depolarisation (Tables 1 and 3), suggesting that in noradrenergic neurones, depolarisation and cAMP-dependent transmitter release evoked by LL are not coupled in an obligatory way.

A

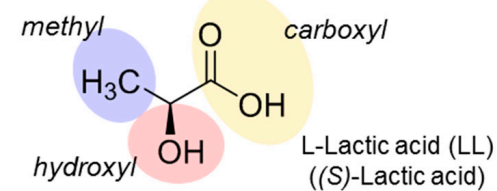

B

$$
{ }_{\mathrm{HO}}^{\mathrm{HO}}=\mathrm{C}_{1}^{\mathrm{H}_{3} \mathrm{C}} \mathrm{CH}_{3}=\mathrm{O}
$$

2-hydroxy-2-propansulfonic acid (HPSA)

$$
\mathrm{H}_{3} \mathrm{C} \underbrace{\mathrm{O}}_{\mathrm{OH}} \mathrm{CH}_{3}
$$

methyl L-lactate (M-LL) ((S)-Methyl lactate)
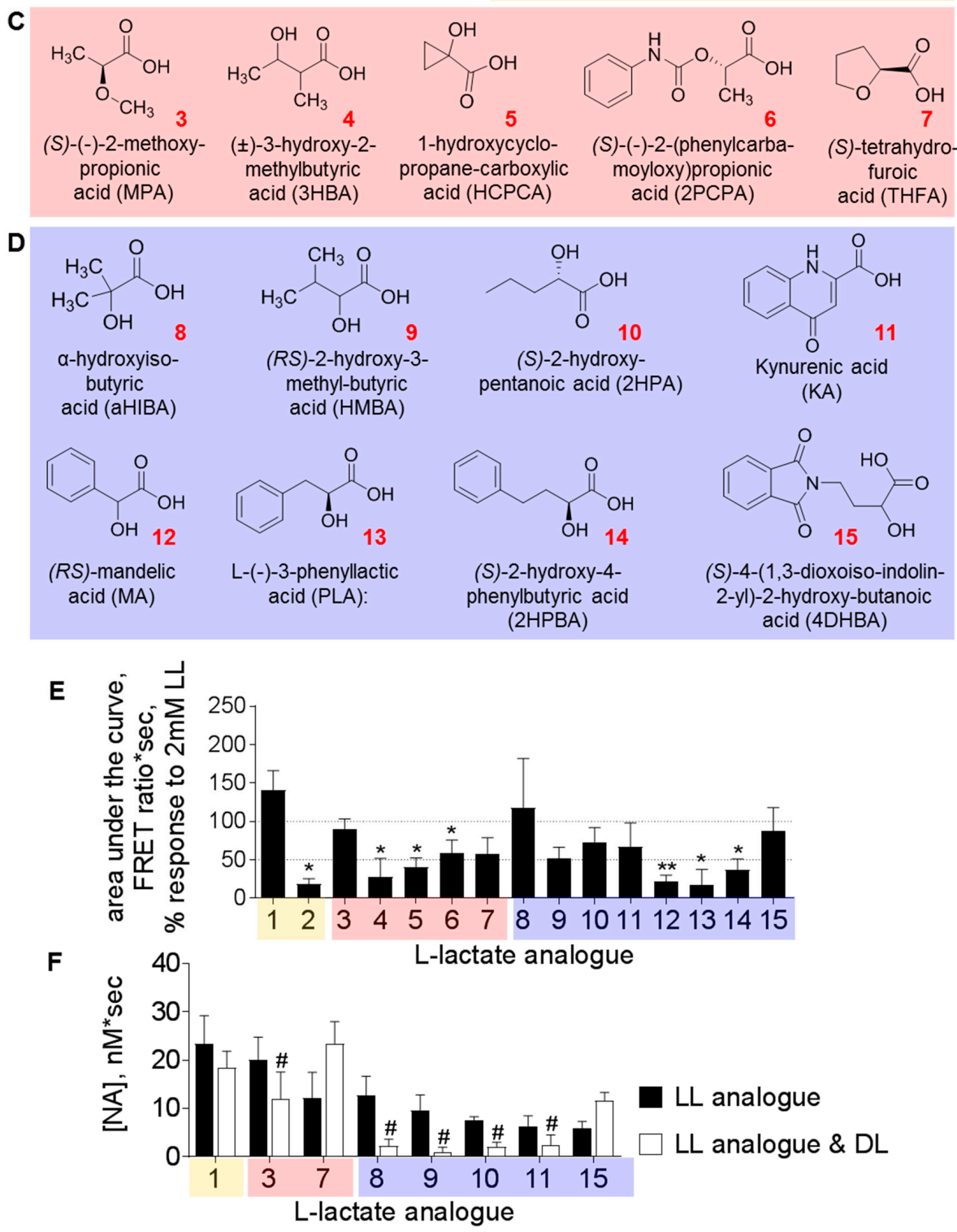

Figure 2. The structure-activity relationship (SAR) between L-lactate analogues and noradrenaline release in locus coeruleus characterises L-lactate binding properties at LLRx. (A) Moieties of the L-lactic (LL) acid molecule. The selection of tested LL analogues had alterations in the carboxyl group (B) (yellow highlight), in the hydroxyl group (C) (red highlight); and in the methyl group (D) (blue highlight). (E) LL analogues 1, 3, 7, 8-11, and $15(2 \mathrm{mM})$ triggered more than 50\% response in noradrenaline-sensitive $\alpha 1$ CNiFER cells as compared to $2 \mathrm{mM} \mathrm{LL}(100 \%)$. The rest of the tested analogues evoked significantly smaller responses compared to $\operatorname{LL}\left(* * p<0.01{ }^{*} p<0.05\right.$ vs $2 \mathrm{mM} \mathrm{LL}$ application for each analogue, paired $t$-test). (F) The effect of analogues $\mathbf{3}$ and 8-11 was blocked by pre-incubation with $200 \mu \mathrm{M}$ D-lactate (DL; ${ }^{\#} p<0.05$ vs the same analogue without DL, paired $t$-test; E/F-data represented as mean \pm SEM). 
Table 3. Depolarisation of locus coeruleus neurones evoked by L-lactate and its analogues that cause D-lactate-sensitive noradrenaline release.

\begin{tabular}{cccc}
\hline LL Analogue (Figure 2) & Cells Analysed (number) & Cells Depolarised (\%) & Vm (mV) \\
\hline LL & 94 & 34 & $7.3 \pm 1.1$ \\
$\mathbf{3}$ & 8 & 0 & \\
$\mathbf{8}$ & 28 & 43 & $6.2 \pm 1.3$ \\
$\mathbf{9}$ & 9 & 67 & $5.3 \pm 1.0$ \\
$\mathbf{1 0}$ & 8 & 25 & \\
$\mathbf{1 1}$ & 7 & 14 & \\
\hline
\end{tabular}

L-lactate (LL) analogue numbers as displayed in Figure 2. Resting membrane potential data $\left(\mathrm{V}_{\mathrm{m}}\right)$ are displayed as mean \pm SEM in cells that showed a response.

\subsection{Orphan GPCRs as Putative Targets of L-Lactate}

We used the DiscoveRx panel of orphan GPCRs (orphanMAX, LeadHunter; Fremont, CA, USA) to screen for the activity of LL $(2-8 \mathrm{mM})$ and filtered the results for those orphans that were expressed in the LC, based on our NGS data (Table 4).

Only one of the orphan receptors on the panel, GPR162, satisfied the DiscoveRx criteria of $>30 \%$ for significant activation by LL (at $8 \mathrm{mM}$ ). The response of several other receptors, however, exceeded 3 times the standard deviation of the baseline. Note that HCA1 (GPR81) did not respond to the maximum concentration of $8 \mathrm{mM}$ LL as employed in our DiscoveRx screen, indicating that this assay might not be suitable for detection of signalling through these low-affinity receptors.

We considered those orphan GPCRs with likely $\mathrm{G}_{\mathrm{s}}$-protein or unknown coupling that were expressed in noradrenergic neurones of the LC, but not in astrocytes, for further testing (Table 4). Receptors were transiently expressed in HEK293 cells and subjected to the GloSensor cAMP assay to test for the response to LL (Table 4; Figure 3). As expected, HEK293 cells transiently transfected with GPR81 showed a concentration-dependent reduction in cAMP accumulation when stimulated with LL (Figure 3A). Another orphan receptor, GPR180, responded with decrease in cAMP to both $1 \mathrm{mM}$ and $10 \mathrm{mM}$ LL (Figure 3B). The only orphan receptor to significantly increase cAMP production with LL in the range of 1-5 mM was GPR137 (Figure 4A,C). In contrast, its paralogue, GPR137B, which is also highly expressed in noradrenergic cells of the LC, did not respond to $2 \mathrm{mM}$ LL (Figure 4B).

The enantiomer of LL, DL $(0.4 \mathrm{mM})$, did not activate GPR137 to increase cAMP production (Figure 4C). Co-application of $0.4 \mathrm{mM}$ DL with $2 \mathrm{mM} \mathrm{LL}$, which in our previous study blocked LL-evoked effects on NA release, did not significantly affect cAMP accumulation in comparison to $2 \mathrm{mM}$ LL application alone (Figure 4C).

Table 4. Screening of heterologously expressed orphan GPCRs for activation by L-lactate.

\begin{tabular}{|c|c|c|c|c|c|c|c|c|c|}
\hline \multirow[b]{2}{*}{ GPCR } & \multirow[b]{2}{*}{ Coupling? } & \multicolumn{3}{|c|}{$\begin{array}{l}\text { DiscoveRx Activation } \\
(\%) \text { by LL (mM) }\end{array}$} & \multicolumn{4}{|c|}{ Expression in LC (NGS) } & \multirow{2}{*}{$\begin{array}{l}\text { cAMP Assay: } \\
\text { Activation by LL } \\
(0.5-10 \mathrm{mM})\end{array}$} \\
\hline & & 2 & 4 & 8 & p29 & p7 & Neuron & Astrocyte & \\
\hline GPR61 & Gs & $-2 \%$ & $16 \%$ & $19 \%$ & 97 & 183 & 163 & 0 & No response \\
\hline GPR81 & $\mathrm{Gi}$ & $1 \%$ & $3 \%$ & $3 \%$ & 0 & 0 & 0 & 0 & Decrease \\
\hline GPR137 & Gs? & $6 \%$ & $4 \%$ & $3 \%$ & 959 & 628 & 196 & 577 & Increase \\
\hline GPR137B & $?$ & nd & nd & nd & 226 & 83 & 140 & 125 & No response \\
\hline GPR146 & $?$ & $-3 \%$ & $10 \%$ & $20 \%$ & 129 & 49 & 6 & 312 & nd \\
\hline GPR155 & RGS? & nd & nd & $n d$ & 842 & 412 & 140 & 36 & No response \\
\hline GPR158 & RGS7 & nd & nd & nd & 1692 & 433 & 613 & 1 & No response \\
\hline GPR162 & $?$ & $-9 \%$ & $15 \%$ & $30 \%$ & 1293 & 1012 & 282 & 64 & No response \\
\hline GPR176 & $\mathrm{Gz}$ & $-8 \%$ & $-2 \%$ & $9 \%$ & 193 & 196 & 190 & 9 & No response \\
\hline GPR180 & Gi? & nd & nd & nd & 768 & 542 & 520 & 83 & Decrease \\
\hline
\end{tabular}

The combination of DiscoveRx panel readout and GloSensor assay for cAMP production suggests further L-lactate (LL)-sensing GPCR candidates. Apart from GPR81, this selection of receptors is expressed in locus coeruleus (LC) neurones at medium to high levels. Coupling information obtained from www.genecards.org. NGS-RNA-Seq by next-generation sequencing; nd-not determined. 
A

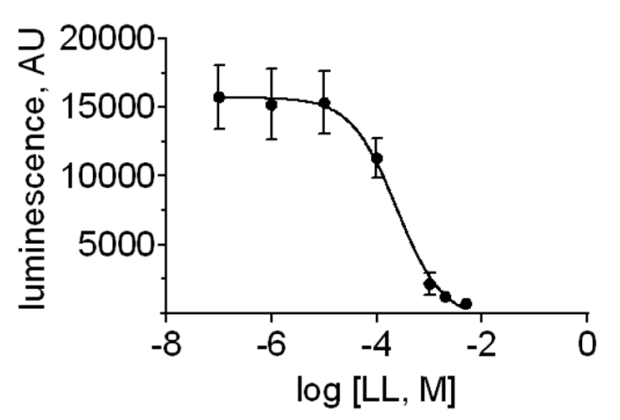

B

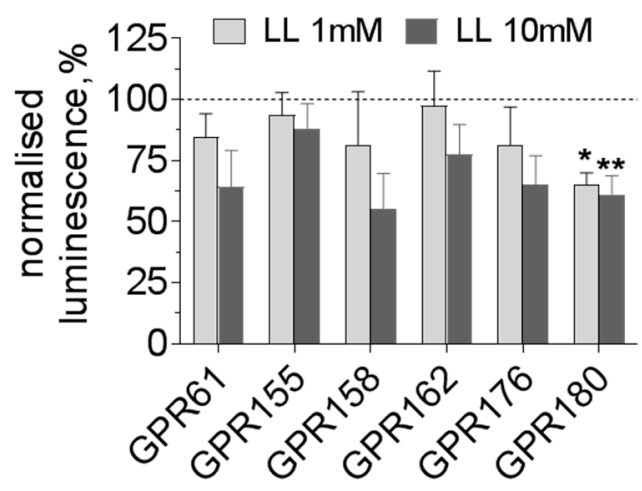

Figure 3. L-lactate activates GPR81- and GPR180-dependent $G_{i}$-protein signalling in HEK293 cells. (A) L-lactate (LL) concentration-dependently decreases cAMP accumulation in HEK293 cells transiently transfected with GPR81 $(0.1 \mu \mathrm{g} / \mu \mathrm{L}$; GloSensor assay; EC $50243 \mu \mathrm{M})$. In order to create an elevated cAMP baseline level, cells were pretreated with $20 \mu \mathrm{M}$ NHK 477, a soluble forskolin analogue. (B) Selected orphan GPCRs present in locus coeruleus neurones were transiently expressed in HEK293 cells (transfection with $0.1 \mu \mathrm{g} / \mu \mathrm{L}$ GPCR expression plasmid). Application of LL led to a significant decrease in cAMP only in GPR180-expressing cells. GloSensor assay: luminescence normalised to baseline in absence of LL; data represented as mean $\pm \mathrm{SEM}$; ${ }^{* *} p<0.01,{ }^{*} p<0.05$ vs no LL stimulation; $n=3$; one-way ANOVA with Dunnett's as post-hoc test.

\section{Discussion}

This study aimed to further characterise LLRx, the LL receptor which mediates the communication between activated astrocytes and noradrenergic neurones [20]. Our previous evidence had suggested that LL acts at an extracellular site and was not consistent with the modulation of $\mathrm{K}_{\mathrm{ATP}}$ channels. Based on the sensitivity of the effect to inhibition of adenylate cyclase or protein kinase A, we hypothesised that LLRx is most likely a GPCR that activates $\mathrm{G}_{\mathrm{s}}$-protein signalling, suggestive of an orphan GPCR or one of the olfactory receptors.

The potency of LL via its action on LLRx $\left(\mathrm{EC}_{50} \sim 0.5 \mathrm{mM}\right.$ ) should be low compared to that of other endogenous GPCR ligands. For example, NA acting at $\beta$-adrenoceptors is around three orders of magnitude more potent (see Supplement in [44]. It is, however, fully consistent with a specific response based on low-affinity binding, given the high physiological extracellular LL concentration in the brain. Indeed, in comparison to the other LL receptors reported to date, HCA1 and OR51E2, the EC 50 of LL at LLRx is around 10-fold lower and appears well correlated with the operational range of brain LL concentrations. It is, therefore, most suitable for mediating a dynamic physiological response to LL.

The experimental disadvantage of a low-affinity ligand-receptor interaction is that it rules out specific pull-down approaches to concentrate and biochemically analyse the receptor. Hence, we adopted an alternative approach to evaluate the properties of the LL-LLRx interaction and to determine an agonist profile for the LLRx-mediated stimulation of NA release.

The carboxyl group seems to be essential for LL's agonist activity as it was intact in all NA-releasing analogues, and methylation of the carboxyl group to form the ester analogue M-LL abolished the effect (2, Figure 2B,E,F). Replacement of the carboxyl group by a more acidic sulfonate group in HPSA (1, Figure 2B) did result in triggering NA release, but eliminated the antagonist effect of DL. This suggests that HPSA acts via a different mechanism than by activation of LLRx. Indeed, it may be that HPSA is decomposing into acetone and sulphuric acid, leading to a false positive result.

The 2-hydroxyl group was intact in most of the active LL analogues, indicating its importance for NA release. Most analogues with 2-OH deletion or modifications, particularly addition of large groups, were inactive, apart from MPA, THFA, and KA (3, 7 Figure 2C, 11, Figure 2D, respectively). The DL-sensitive effect of MPA indicates that the hydroxyl group may act as a hydrogen bond acceptor, but hydrogen bond donation is not necessary to trigger NA release. THFA (7, Figure 2C) can be thought of as a conformationally restricted analogue of LL and MPA (3, Figure 2C), while HCPCA 
(5, Figure 2C) is a conformationally restricted analogue of LL and aHIBA (8, Figure 2D). THFA and HCPCA were less active than the parent molecules MPA and aHIBA, respectively, suggesting that the conformations of THFA and HCPCA are not optimal for interaction with LLRx. Kynurenic acid (KA, 11, Figure 2D) can be thought of as a conformationally restricted analogue of LL in which the $\mathrm{NH}$ group acts as a mimic of the $\mathrm{OH}$ group of LL and the methyl group of LL is incorporated into the ring structure. The 4-oxo group of KA, which is a hydrogen bond acceptor, may also play a role in interacting with LLRx. Future SAR studies are needed to explore this possibility.

Addition of a second methyl group in the $\alpha$-position, as in aHIBA (8, Figure 2D), or extension of the carbon chain from the methyl group as in HMBA and 2HPA $(\mathbf{9}, \mathbf{1 0}$, Figure 2D), supports activation of LLRx. However, large lipophilic residues replacing or added as substituents to the methyl group prevent DL-sensitive NA release (12-15, Figure 2D), indicating a limitation of size in the binding pocket.

The comparison of the analogues that cause NA release and those that evoke membrane depolarisation shows that, in noradrenergic neurones, NA release can be evoked without necessarily increasing the cells' electrical excitability. This is unsurprising, given previous evidence for cAMP-mediated increase in exocytosis [45]. In fact, extensive evidence indicates that depolarisation should not be the primary mechanism regulating NA release, because noradrenergic neurones are characteristically depolarised at rest. Membrane potentials of LC neurones, in vitro as well as in vivo, are typically near $-50 \mathrm{mV}$ (Supplementary Materials Figure S2; [20,46-48]. Moreover, LC neurones in vivo and in slices tend to generate a constant low-frequency stream of action potentials while their excitation by a sensory stimulus triggers only a very short $(\sim 20 \mathrm{~ms})$ barrage of $3-5$ additional action potentials which is followed by a long period of quiescence lasting hundreds of milliseconds $[49,50]$. Therefore, the conventional logic of neuronal networks where high-frequency action potential activity triggers release of a neurotransmitter, such as glutamate, does not apply to noradrenergic neurones. A mechanism which sensitises the NA release machinery and potentiates NA release to the steady-state level of intracellular $\mathrm{Ca}^{2+}$ (with or without additional depolarisation) should be a much more effective way to control NA release.

It is also important to note that the chemicals tested here can affect multiple targets. Kynurenic acid, for example, while effectively triggering DL-sensitive NA release, is also a well-known glutamate receptor antagonist [51]. Blocking of glutamate receptors theoretically should lead to a decrease rather than an increase in neuronal excitability, but KA nevertheless triggered release of NA.

Whilst beyond the scope of the current study, analogues that failed to produce a positive response in the NA release assay may have antagonist or weak partial agonist properties. If such compounds are identified and optimised, they may be expected to facilitate future studies to characterise the physiological and pathophysiological roles of this astrocytic signalling pathway.

The DiscoveRx panel screening is based on $\beta$-arrestin-induced internalisation and should be independent of the type of G-protein the receptor couples with. The approach is not very sensitive and, in the case of low-potency agonists such as LL, relatively high concentrations of agonist need to be employed, potentially leading to nonspecific effects. Only few concentration-dependent responses to LL $(2-8 \mathrm{mM})$ were detected. When following up on the effect of LL on GPR162, we were unable to confirm a LL-induced change in cAMP production in transiently transfected HEK293 cells. This suggests that GPR162 does not signal via $\mathrm{G}_{\mathrm{s}}$-proteins and is therefore not consistent with LLRx function.

We acknowledge that we selected orphan candidates with medium to high expression levels in $\mathrm{LC}$ and with either unknown or proposed $\mathrm{G}_{\mathrm{s}}$-coupling in order to determine their cAMP response to LL (Table 4). Of these, only GPR137 produced a concentration-dependent but DL-insensitive increase in cAMP, making it an interesting candidate for further study. GPR137 has two paralogues, GPR137B and GPR137C, which are located on different chromosomes. Unusually for GPCRs, all three paralogues contain introns, raising the possibility of multiple variants through alternative splicing. GPR137 has been suggested to play a role in the proliferation of malignant tumours, but its functional significance for the brain has not yet been explored [52,53]. Neither ligands nor physiological actions of 
GPR137B and GPR137C are currently established. However, as the cAMP response was not inhibited by co-application of DL, GPR137 does not fulfil all properties proposed for "LLRx" (Figure 4C).

A

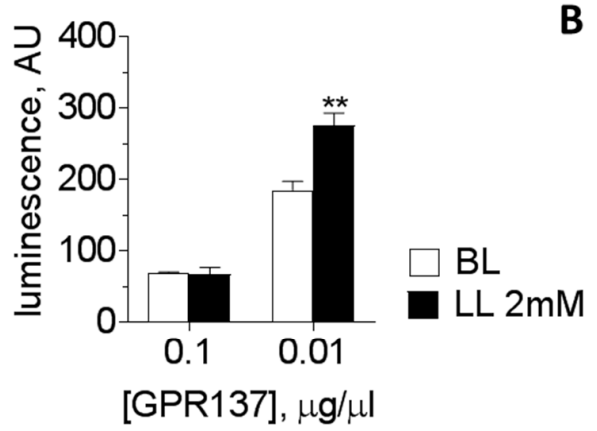

B

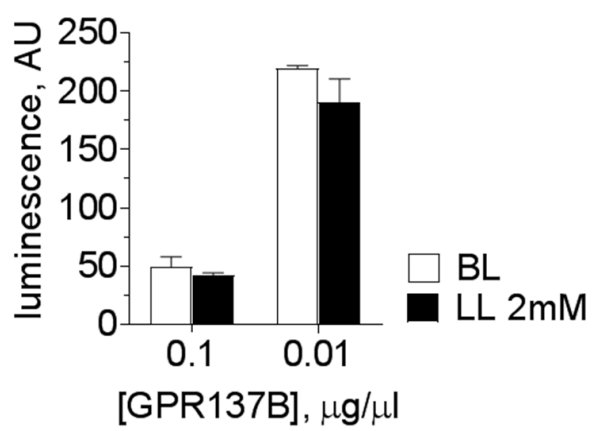

C



Figure 4. L-lactate stimulates GPR137-dependent cAMP accumulation in HEK293 cells. (A) HEK293 cells transiently transfected with GPR137 $(0.01 \mu \mathrm{g} / \mu \mathrm{L})$ respond to $2 \mathrm{mM}$ L-lactate (LL) with cAMP accumulation (GloSensor assay, $n=3,{ }^{* *} p<0.01$ vs baseline (BL), one-way ANOVA with Tukey's post-hoc test). (B) HEK293 cells expressing GPR137B do not respond to $2 \mathrm{mM} \mathrm{LL}$. (C) Concentration range of LL and DL effects on cAMP in HEK293 cells transiently transfected with GPR137 $(0.01 \mu \mathrm{g} / \mu \mathrm{L})$. LL significantly increases cAMP at concentrations $\geq 1 \mathrm{mM}$. D-lactate (DL) elicits no response and does not significantly inhibit the effect of $2 \mathrm{mM} \mathrm{LL}$ (data are shown as mean $\pm \mathrm{SEM}$; $n$ values for each dataset are represented in the respective columns; ${ }^{* * *} p<0.0001,{ }^{*} p<0.05$ vs control, one-way ANOVA with Tukey's post-hoc test).

Looking into the future, the list of potential LL receptor candidates is by no means complete if we include orphan GPCRs with low to medium expression levels such as GPR146 and others (not shown) to explore further as targets for LL-mediated signalling. Since LL-mediated release of NA is implicated in regulation of sleep/wake and attention states, learning and memory, and cardiorespiratory control, a better understanding of-and pharmacological tools to control—this signalling axis may have significant health implications.

Supplementary Materials: The following are available online at http://www.mdpi.com/2571-6980/1/2/25/s1, Figure S1. L-lactate evokes noradrenaline release from organotypic brain slices cultures as confirmed by using $\alpha 1$ CNiFER cells. Figure S2. L-lactate and analogues excite noradrenergic LC neurones.

Author Contributions: Conceptualisation: S.K., A.G.T.; data acquisition and analysis: V.M., S.R.-N., K.K., M.D.B.; advice on LL analogue chemistry: D.J.; NGS-M.D.B., M.J.H.; manuscript writing and editing: A.G.T., V.M., S.K.

Funding: This work was supported by grants from BBSRC BB/L019396/1, and MRC MR/L020661/1.

Acknowledgments: David Kleinfeld for his gift of CNiFER cells, Lesley Arberry for expert technical support, Andrew Herman for support with FACS sorting.

Conflicts of Interest: The authors declare no conflict of interest. 


\section{References}

1. Oe, Y.; Baba, O.; Ashida, H.; Nakamura, K.C.; Hirase, H. Glycogen distribution in the microwave-fixed mouse brain reveals heterogeneous astrocytic patterns. GLIA 2016, 64, 1532-1545. [CrossRef] [PubMed]

2. Locasale, J.W.; Cantley, L.C. Metabolic flux and the regulation of mammalian cell growth. Cell. Metab. 2011, 14, 443-451. [CrossRef] [PubMed]

3. Dienel, G.A. Lack of appropriate stoichiometry: Strong evidence against an energetically important astrocyte-neuron lactate shuttle in brain. J. Neurosci. Res. 2017, 95, 2103-2125. [CrossRef] [PubMed]

4. Abi-Saab, W.M.; Maggs, D.G.; Jones, T.; Jacob, R.; Srihari, V.; Thompson, J.; Kerr, D.; Leone, P.; Krystal, J.H.; Spencer, D.D.; et al. Striking differences in glucose and lactate levels between brain extracellular fluid and plasma in conscious human subjects: Effects of hyperglycemia and hypoglycemia. J. Cereb. Blood Flow Metab. 2002, 22, 271-279. [CrossRef] [PubMed]

5. Mosienko, V.; Teschemacher, A.G.; Kasparov, S. Is L-lactate a novel signaling molecule in the brain? J. Cereb. Blood Flow Metab. 2015, 35, 1069-1075. [CrossRef] [PubMed]

6. Machler, P.; Wyss, M.T.; Elsayed, M.; Stobart, J.; Gutierrez, R.; von Faber-Castell, A.; Kaelin, V.; Zuend, M.; San Martin, A.; Romero-Gomez, I.; et al. In Vivo Evidence for a Lactate Gradient from Astrocytes to Neurons. Cell Metab. 2016, 23, 94-102. [CrossRef] [PubMed]

7. Supplie, L.M.; Duking, T.; Campbell, G.; Diaz, F.; Moraes, C.T.; Gotz, M.; Hamprecht, B.; Boretius, S.; Mahad, D.; Nave, K.A. Respiration-Deficient Astrocytes Survive as Glycolytic Cells In Vivo. J. Neurosci. 2017, 37, 4231-4242. [CrossRef] [PubMed]

8. Fernandez-Moncada, I.; Ruminot, I.; Robles-Maldonado, D.; Alegria, K.; Deitmer, J.W.; Barros, L.F. Neuronal control of astrocytic respiration through a variant of the Crabtree effect. Proc. Natl. Acad. Sci. USA 2018, 115, 1623-1628. [CrossRef] [PubMed]

9. Pellerin, L.; Magistretti, P.J. Sweet sixteen for ANLS. J. Cereb. Blood Flow Metab. 2011, 32, 1152-1166. [CrossRef] [PubMed]

10. Weber, B.; Barros, L.F. The Astrocyte: Powerhouse and Recycling Center. Cold Spring Harb. Perspect. Biol. 2015, 7, a020396. [CrossRef] [PubMed]

11. Suzuki, A.; Stern, S.A.; Bozdagi, O.; Huntley, G.W.; Walker, R.H.; Magistretti, P.J.; Alberini, C.M. Astrocyte-neuron lactate transport is required for long-term memory formation. Cell 2011, 144, 810-823. [CrossRef] [PubMed]

12. Newman, L.A.; Korol, D.L.; Gold, P.E. Lactate produced by glycogenolysis in astrocytes regulates memory processing. PLoS ONE 2011, 6, e28427. [CrossRef] [PubMed]

13. Alberini, C.M.; Cruz, E.; Descalzi, G.; Bessieres, B.; Gao, V. Astrocyte glycogen and lactate: New insights into learning and memory mechanisms. GLIA 2017, 66, 1244-1262. [CrossRef] [PubMed]

14. Clasadonte, J.; Scemes, E.; Wang, Z.; Boison, D.; Haydon, P.G. Connexin 43-Mediated Astroglial Metabolic Networks Contribute to the Regulation of the Sleep-Wake Cycle. Neuron 2017, 95, 1365-1380. [CrossRef] [PubMed]

15. Naylor, E.; Aillon, D.V.; Barrett, B.S.; Wilson, G.S.; Johnson, D.A.; Johnson, D.A.; Harmon, H.P.; Gabbert, S.; Petillo, P.A. Lactate as a biomarker for sleep. Sleep 2012, 35, 1209-1222. [CrossRef] [PubMed]

16. Rempe, M.J.; Wisor, J.P. Cerebral lactate dynamics across sleep/wake cycles. Front Comput. Neurosci. 2014, 8, 174. [CrossRef] [PubMed]

17. Carrard, A.; Elsayed, M.; Margineanu, M.; Boury-Jamot, B.; Fragniere, L.; Meylan, E.M.; Petit, J.M.; Fiumelli, H.; Magistretti, P.J.; Martin, J.L. Peripheral administration of lactate produces antidepressant-like effects. Mol. Psychiatry 2018, 23, 392-399. [CrossRef] [PubMed]

18. Reiach, J.S.; Li, P.P.; Warsh, J.J.; Kish, S.J.; Young, L.T. Reduced adenylyl cyclase immunolabeling and activity in postmortem temporal cortex of depressed suicide victims. J. Affect Disord. 1999, 56, 141-151. [CrossRef]

19. Vardjan, N.; Chowdhury, H.H.; Horvat, A.; Velebit, J.; Malnar, M.; Muhic, M.; Kreft, M.; Krivec, S.G.; Bobnar, S.T.; Mis, K.; et al. Enhancement of Astroglial Aerobic Glycolysis by Extracellular Lactate-Mediated Increase in cAMP. Front Mol. Neurosci. 2018, 11, 148. [CrossRef] [PubMed]

20. Tang, F.; Lane, S.; Korsak, A.; Paton, J.F.; Gourine, A.V.; Kasparov, S.; Teschemacher, A.G. Lactate-mediated glia-neuronal signaling in the mammalian brain. Nat. Commun. 2014, 5, 3284. [CrossRef] [PubMed] 
21. Yang, J.; Ruchti, E.; Petit, J.M.; Jourdain, P.; Grenningloh, G.; Allaman, I.; Magistretti, P.J. Lactate promotes plasticity gene expression by potentiating NMDA signaling in neurons. Proc. Natl. Acad. Sci. USA 2014, 111, 12228-12233. [CrossRef] [PubMed]

22. Lee, D.C.; Sohn, H.A.; Park, Z.Y.; Oh, S.; Kang, Y.K.; Lee, K.M.; Kang, M.; Jang, Y.J.; Yang, S.J.; Hong, Y.K.; et al. A lactate-induced response to hypoxia. Cell 2015, 161, 595-609. [CrossRef] [PubMed]

23. Parsons, M.P.; Hirasawa, M. ATP-sensitive potassium channel-mediated lactate effect on orexin neurons: Implications for brain energetics during arousal. J. Neurosci. 2010, 30, 8061-8070. [CrossRef] [PubMed]

24. Cai, T.Q.; Ren, N.; Jin, L.; Cheng, K.; Kash, S.; Chen, R.; Wright, S.D.; Taggart, A.K.; Waters, M.G. Role of GPR81 in lactate-mediated reduction of adipose lipolysis. Biochem. Biophys. Res. Commun. 2008, 377, 987-991. [CrossRef] [PubMed]

25. Liu, C.; Wu, J.; Zhu, J.; Kuei, C.; Yu, J.; Shelton, J.; Sutton, S.W.; Li, X.; Yun, S.J.; Mirzadegan, T.; et al. Lactate inhibits lipolysis in fat cells through activation of an orphan G-protein-coupled receptor, GPR81. J. Biol. Chem. 2009, 284, 2811-2822. [CrossRef] [PubMed]

26. Lauritzen, K.H.; Morland, C.; Puchades, M.; Holm-Hansen, S.; Hagelin, E.M.; Lauritzen, F.; Attramadal, H.; Storm-Mathisen, J.; Gjedde, A.; Bergersen, L.H. Lactate receptor sites link neurotransmission, neurovascular coupling, and brain energy metabolism. Cereb. Cortex 2014, 24, 2784-2795. [CrossRef] [PubMed]

27. Morland, C.; Lauritzen, K.H.; Puchades, M.; Holm-Hansen, S.; Andersson, K.; Gjedde, A.; Attramadal, H.; Storm-Mathisen, J.; Bergersen, L.H. The lactate receptor, G-protein-coupled receptor 81/hydroxycarboxylic acid receptor 1, Expression and action in brain. J. Neurosci. Res. 2015, 93, 1045-1055. [CrossRef] [PubMed]

28. Bozzo, L.; Puyal, J.; Chatton, J.Y. Lactate modulates the activity of primary cortical neurons through a receptor-mediated pathway. PLoS ONE 2013, 8, e71721. [CrossRef] [PubMed]

29. Chang, A.J.; Ortega, F.E.; Riegler, J.; Madison, D.V.; Krasnow, M.A. Oxygen regulation of breathing through an olfactory receptor activated by lactate. Nature 2015, 527, 240-244. [CrossRef] [PubMed]

30. Hosford, P.S.; Mosienko, V.; Kishi, K.; Jurisic, G.; Seuwen, K.; Kinzel, B.; Ludwig, M.G.; Wells, J.A.; Christie, I.N.; Koolen, L.; et al. CNS distribution, signalling properties and central effects of G-protein coupled receptor 4. Neuropharmacology 2018, 138, 381-392. [CrossRef] [PubMed]

31. Conzelmann, S.; Levai, O.; Bode, B.; Eisel, U.; Raming, K.; Breer, H.; Strotmann, J. A novel brain receptor is expressed in a distinct population of olfactory sensory neurons. Eur. J. Neurosci. 2000, 12, 3926-3934. [CrossRef] [PubMed]

32. Torres-Torrelo, H.; Ortega-Saenz, P.; Macias, D.; Omura, M.; Zhou, T.; Matsunami, H.; Johnson, R.S.; Mombaerts, P.; Lopez-Barneo, J. The role of Olfr78 in the breathing circuit of mice. Nature 2018, 561, E33-E40. [CrossRef] [PubMed]

33. McBryde, F.D.; Abdala, A.P.; Hendy, E.B.; Pijacka, W.; Marvar, P.; Moraes, D.J.; Sobotka, P.A.; Paton, J.F. The carotid body as a putative therapeutic target for the treatment of neurogenic hypertension. Nat. Commun. 2013, 4, 2395. [CrossRef] [PubMed]

34. Marina, N.; Tang, F.; Figueiredo, M.; Mastitskaya, S.; Kasimov, V.; Mohamed-Ali, V.; Roloff, E.; Teschemacher, A.G.; Gourine, A.V.; Kasparov, S. Purinergic signalling in the rostral ventro-lateral medulla controls sympathetic drive and contributes to the progression of heart failure following myocardial infarction in rats. Basic Res. Cardiol. 2013, 108, 317. [CrossRef] [PubMed]

35. Yuan, T.T.; Toy, P.; McClary, J.A.; Lin, R.J.; Miyamoto, N.G.; Kretschmer, P.J. Cloning and genetic characterization of an evolutionarily conserved human olfactory receptor that is differentially expressed across species. Gene 2001, 278, 41-51. [CrossRef]

36. Weber, M.; Pehl, U.; Breer, H.; Strotmann, J. Olfactory receptor expressed in ganglia of the autonomic nervous system. J. Neurosci. Res. 2002, 68, 176-184. [CrossRef] [PubMed]

37. Mosienko, V.; Chang, A.J.; Alenina, N.; Teschemacher, A.G.; Kasparov, S. Rodents and humans are able to detect the odour of L-Lactate. PLoS ONE 2017, 12, e0178478. [CrossRef] [PubMed]

38. Ludwig, M.G.; Vanek, M.; Guerini, D.; Gasser, J.A.; Jones, C.E.; Junker, U.; Hofstetter, H.; Wolf, R.M.; Seuwen, K. Proton-sensing G-protein-coupled receptors. Nature 2013, 425, 93-98. [CrossRef] [PubMed]

39. Kumar, N.N.; Velic, A.; Soliz, J.; Shi, Y.; Li, K.; Wang, S.; Weaver, J.L.; Sen, J.; Abbott, S.B.; Lazarenko, R.M.; et al. PHYSIOLOGY. Regulation of breathing by $\mathrm{CO}_{2}$ requires the proton-activated receptor GPR4 in retrotrapezoid nucleus neurons. Science 2015, 348, 1255-1260. [CrossRef] [PubMed] 
40. Teschemacher, A.G.; Wang, S.; Lonergan, T.; Duale, H.; Waki, H.; Paton, J.F.; Kasparov, S. Targeting specific neuronal populations in the rat brainstem using adeno- and lentiviral vectors: Applications for imaging and studies of cell function. Exp. Physiol. 2005, 90, 61-69. [CrossRef] [PubMed]

41. Figueiredo, M.; Lane, S.; Stout, R.F., Jr.; Liu, B.; Parpura, V.; Teschemacher, A.G.; Kasparov, S. Comparative analysis of optogenetic actuators in cultured astrocytes. Cell Calcium 2014, 56, 208-214. [CrossRef] [PubMed]

42. Lobo, M.K.; Karsten, S.L.; Gray, M.; Geschwind, D.H.; Yang, X.W. FACS-array profiling of striatal projection neuron subtypes in juvenile and adult mouse brains. Nat. Neurosci. 2006, 9, 443-452. [CrossRef] [PubMed]

43. Muller, A.; Joseph, V.; Slesinger, P.A.; Kleinfeld, D. Cell-based reporters reveal in vivo dynamics of dopamine and norepinephrine release in murine cortex. Nat. Methods 2014, 11, 1245-1252. [CrossRef] [PubMed]

44. Liu, B.; Mosienko, V.; Vaccari, C.B.; Prokudina, D.; Huentelman, M.; Teschemacher, A.G.; Kasparov, S. Glioand neuro-protection by prosaposin is mediated by orphan G-protein coupled receptors GPR37L1 and GPR37. GLIA 2018. [CrossRef] [PubMed]

45. Chavez-Noriega, L.E.; Stevens, C.F. Increased transmitter release at excitatory synapses produced by direct activation of adenylate cyclase in rat hippocampal slices. J. Neurosci. 1994, 14, 310-317. [CrossRef] [PubMed]

46. Williams, J.T.; Bobker, D.H.; Harris, G.C. Synaptic potentials in locus coeruleus neurons in brain slices. Prog. Brain Res. 1991, 88, 167-172. [PubMed]

47. Pepper, C.M.; Henderson, G. Opiates and opioid peptides hyperpolarize locus coeruleus neurons in vitro. Science 1980, 209, 394-395. [CrossRef] [PubMed]

48. Aghajanian, G.K.; Vandermaelen, C.P. $\alpha$ 2-adrenoceptor-mediated hyperpolarization of locus coeruleus neurons: Intracellular studies in vivo. Science 1982, 215, 1394-1396. [CrossRef] [PubMed]

49. Cedarbaum, J.M.; Aghajanian, G.K. Activation of locus coeruleus neurons by peripheral stimuli: Modulation by a collateral inhibitory mechanism. Life Sci. 1978, 23, 1383-1392. [CrossRef]

50. Foote, S.L.; Aston-Jones, G.; Bloom, F.E. Impulse activity of locus coeruleus neurons in awake rats and monkeys is a function of sensory stimulation and arousal. Proc. Natl. Acad. Sci. USA 1980, 77, 3033-3037. [CrossRef] [PubMed]

51. Alt, A.; Weiss, B.; Ogden, A.M.; Knauss, J.L.; Oler, J.; Ho, K.; Large, T.H.; Bleakman, D. Pharmacological characterization of glutamatergic agonists and antagonists at recombinant human homomeric and heteromeric kainate receptors in vitro. Neuropharmacology 2004, 46, 793-806. [CrossRef] [PubMed]

52. Zong, G.; Wang, H.; Li, J.; Xie, Y.; Bian, E.; Zhao, B. Inhibition of GPR137 expression reduces the proliferation and colony formation of malignant glioma cells. Neurol. Sci. 2014, 35, 1707-1714. [CrossRef] [PubMed]

53. Mager, L.F.; Koelzer, V.H.; Stuber, R.; Thoo, L.; Keller, I.; Koeck, I.; Langenegger, M.; Simillion, C.; Pfister, S.P.; Faderl, M.; et al. The ESRP1-GPR137 axis contributes to intestinal pathogenesis. Elife 2017, 6, e28366. [CrossRef] [PubMed]

(C) 2018 by the authors. Licensee MDPI, Basel, Switzerland. This article is an open access article distributed under the terms and conditions of the Creative Commons Attribution (CC BY) license (http:/ / creativecommons.org/licenses/by/4.0/). 